Policy Research Working Paper $\quad 4502$

\title{
Does Hepatitis B Infection or Son Preference Explain the Bulk of Gender Imbalance in China? :
}

\author{
A Review of the Evidence
}

Monica Das Gupta

The World Bank

Development Research Group

Human Development and Public Services Team

January 2008 
Policy Research Working Paper 4502

\section{Abstract}

China has a large deficit of females, and public policies have sought to reduce the son preference that is widely believed to cause this. Recently a study has suggested that up to 75 percent of this deficit is attributable to hepatitis B infection, indicating that immunization programs should form the first plank of policy interventions. However, a large medical dataset from Taiwan (China) shows that hepatitis B infection raises women's probability of having a son by only 0.25

percent. And demographic data from China show that the only group of women who have elevated probabilities

of bearing a son are those who have already borne daughters. This pattern makes it difficult to see how any biological factor can explain a large part of the imbalance in China's sex ratios at birth-unless it can be shown that it somehow selectively affects those who have borne girls, or causes them to first bear girls and then boys. The Taiwanese data suggest that this is not the case with hepatitis $B$, since its impact is unaffected by the sex composition of previous births. The data support the cultural, rather than the biological, explanation for the "missing women."

This paper-a product of the Human Development and Public Services Team, Development Research Group—is part of a larger effort in the department to study social institutions and development outcomes. Policy Research Working Papers are also posted on the Web at http://econ.worldbank.org. The author may be contacted at mdasgupta@worldbank.org.

The Policy Research Working Paper Series disseminates the findings of work in progress to encourage the exchange of ideas about development issues. An objective of the series is to get the findings out quickly, even if the presentations are less than fully polished. The papers carry the names of the authors and should be cited accordingly. The findings, interpretations, and conclusions expressed in this paper are entirely those of the authors. They do not necessarily represent the views of the International Bank for Reconstruction and Development/World Bank and its affiliated organizations, or those of the Executive Directors of the World Bank or the governments they represent. 


\title{
Does Hepatitis B infection or son preference explain the bulk of gender
} imbalance in China? : a review of the evidence

\author{
Monica Das Gupta ${ }^{1}$
}

\footnotetext{
${ }^{1}$ Development Research Group, The World Bank, Washington DC 20433, USA. Email: mdasgupta@worldbank.org
} 
China has a very large deficit of females, ${ }^{1}$ and public policies have sought hard to reduce the son preference which is widely believed to cause this. The Chinese government has sought to increase gender equity through a wide range of interventions aimed at changing people's perception that girls are less desirable than boys, as well as to bring women firmly into public life. These interventions include, inter alia, vigorous media campaigns to change ideas about gender roles and equity; legislation to enhance gender equity; and sponsoring grassroots women's organizations. ${ }^{2}$ Financial incentives to parents to raise daughters are yet another tool used to this end: they were used by some Chinese clans even in the nineteenth century (Hsu 1948), and revived recently by the Chinese government (Xinhua 2006).

The assumption underlying such policies is that a strong preference for sons is driving the imbalance in sex ratios. Recently, Emily Oster has strongly challenged this assumption, arguing that up to 75 percent of the female deficit in China can be accounted for by the high prevalence of hepatitis B infection (Oster 2005). This would suggest that instead of focusing primarily on the difficult task of altering parental preference for sons, the first plank of policy interventions should instead be the much simpler task of immunizing people against hepatitis $\mathrm{B}$.

There is indeed much evidence that biological factors drive gender differentials in health outcomes. ${ }^{3}$ Studies have also shown that the overall sex ratio at birth in Sweden rose by a couple of percentage points over some centuries as women's nutritional status improved, ${ }^{4}$ and it is possible that some biological factors could have a much larger impact on sex ratios at birth. We therefore consider Oster's hypothesis carefully, reviewing the demographic and medical evidence for and against it. We conclude that the data indicate that hepatitis B infection has a very marginal effect on the proportion of "missing girls" in China. Further, we conclude that the patterns of sex ratio at birth in China (as also in other Asian countries) are difficult to reconcile with a large role of biological factors of any kind.

\section{Studies of the relationship between HBV status and sex ratios at birth}

\section{Evidence from micro-studies}

Six micro-studies carried out by medical scientists researching hepatitis B found a relationship between this disease and the sex ratio of births. Blumberg (2006a) summarizes these results:

"In a study in Greece, families in which either parent was a carrier of HBV had a higher ratio of boys to girls than in families where the parents (particularly the mother) had antiHBs (Table 1).... Similar studies were done in five other populations; they were consistent with the initial results."

Chahnazarian et al. (1988) summarized the results of these studies. They noted that the populations studied were very small and therefore the sex ratios fluctuate between the studies. Thus the precise magnitude of the effect is unclear, although the pattern is clear. They tried hard to dissect the data from three studies which included data on the hepatitis B infection status (HBV status) of both parents, to see whether the father's or the mother's carrier status had a larger effect, but concluded that "It is not clear whether hepatitis B antigen (carrier status) in the father and in the mother has differential effects on the sex ratio at birth." Such questions have a potential relevance for the medical sciences which goes far beyond that of sex ratios at birth. For example, Blumberg (1976) points out that "This connection of HBV with sex selection may also 
explain why there is a greater likelihood of rejection of male kidneys by renal patients with antiHBs, and indicate how kidneys can be better selected for transplantation”.

\section{Oster's (2005) study}

Struck by these findings, Oster (2005) set out to test them on a population level in a large number of countries. She uses a variety of data and analytical approaches, including cross-country analyses, time-series evidence using a natural experiment based on vaccination campaigns in Alaska and Taiwan (China), and finally an estimation of the percent of the female deficit in China and India that is attributable to hepatitis B.

This is not an easy task. ${ }^{5}$ Firstly, the estimates of the prevalence of hepatitis B have to be derived from scattered studies, which often represent a minuscule fraction of the country's population. As she says: "HBV prevalence is calculated as by aggregating published studies.... Only countries with more than 2500 people tested for HBV (combining all studies) are used in the analysis." (Oster 2005: footnote to Table 10, parentheses mine). Secondly, she derives an indirect estimate of the effect of HBV status on the sex ratio at birth, since the direct estimates from the microstudies were based on such small numbers.

She finds that her cross-country analysis shows a clear correlation between the sex ratio at birth and the prevalence of hepatitis B. However, she notes that due to issues of data quality, these regressions omit data from Sub-Saharan Africa, where the sex ratio at birth is low and levels of HBV prevalence are high (Oster 2005:1196). Below we discuss that the issues of data quality she raises for Africa are applicable also to many other developing countries which she includes in her analysis — including India, which she analyzes extensively.

She also finds that in Alaska the vaccination campaigns clearly reduced the sex ratio at birth, but that this relationship is less clear in Taiwan (China). In fact, the Taiwanese vital statistics show that the sex ratio at birth hovered around 109 in the years 1996-2002, and rose slightly to 110 in 2003-2004. ${ }^{6}$ This does not suggest that the vaccination campaign had any significant effect on the sex ratio at birth, since as she says the vaccination campaign started in 1984, so "women who are vaccinated in 1984 would be 15 by 1999”.

She then calculates the proportion of "missing women" in China and India that can be explained by the prevalence of hepatitis B, combining her estimates of "the prevalence of hepatitis B and estimates of the effect of hepatitis on the sex ratio at birth to estimate and adjust the number of missing women." These appear to be estimates of the impact only of the mother's (not the father's) HBV status, since she states that the prevalence data pertain to pregnant women only (Oster 2005: footnote to Table 10).

Using these estimates of HBV prevalence and impact on the sex ratio at birth, she estimates that up to 75 percent of the "missing women" in China in the early 1990s is attributable to parental infection with hepatitis B. Her conclusions are striking, and have received much attention. ${ }^{7}$ Given their strong implications for policy, they warrant deeper exploration with more robust data. 


\section{Lin and Luoh's (2007) study from Taiwan (China)}

Fortunately, there is a very large national longitudinal dataset from Taiwan (China), which permits a robust estimation of the impact of mother's HBV status on sex ratios at birth. These data were collected for a national Hepatitis B immunization program, covering up to 90 percent of births. It was especially important to test pregnant women's HBV status, because an additional dose of Hepatitis B immune globulin had to be given within 24 hours of birth to babies born to women who had tested positive.

Using the data collected between 1988 and 1999, Lin and Luoh (2007) were able to track the sex ratio of births to women whose HBV status was known. They found that women who were infected had only a 0.25 percent higher probability of having a son than other women. With a prevalence of hepatitis B infection as high as 15 percent in the population, this translates into an increase of only 0.16 percent in the overall sex ratio at birth, raising it from a baseline of 105 to 105.165. The sex ratio at birth for all the births in the dataset was 109, so the exercise of son preference accounts for all but a tiny part of the elevation in the overall sex ratio at birth.

Oster estimates that the prevalence of HBV among pregnant women in China is $11.24 \%$, and that this should result in a sex ratio at birth of 1.10 (2005:Table 10). This is the basis for her estimate that HBV accounts for the bulk of excess male births in China (Oster 2005: 1201-2). However, the findings from the detailed medical dataset from Taiwan (China), indicate that she has massively overestimated the impact of maternal hepatitis B infection on the sex ratio at birth.

\section{Oster's (2007) new hypothesis}

In response to Lin and Luoh's (2007) study, Oster has revised the premise of her argument. She now concludes that the effect of HBV on the sex ratio at birth is driven largely by the father's HBV status, and that mother's HBV status plays at most a much weaker role (Blumberg and Oster 2007). As in her previous paper, she uses multiple approaches to arrive at her conclusions ${ }^{8}$ : "We present three pieces of evidence that this may be the case. First, using two of the original datasets on this topic we find that father's infection is more strongly correlated with sex ratio than mother's infection. Second, in population-level data from Taiwan we find that paternal cohort infection rates are more important that maternal cohort infection rates. Finally, we show using the IPUMS dataset that children born in the United States to men born in China are more likely to be boys, but this finding does not hold for children born to women from China."

Each of these analytical approaches raises some questions. First, she revisits the three individuallevel datasets on the basis of which Chahnazarian, Blumberg and London (1988) concluded that sex ratios at birth were elevated if either parent was an HBV carrier, and that the data did not permit them to conclude that one parent's status was more important that the other's. Oster selects two of these three datasets (Greece 1 and the Philippines), and runs regressions on them to show that only the father's HBV status is significantly associated with a more masculine sex ratio at birth, not the mother's. This conclusion is at odds with the previous analyses.

This conclusion is also at odds with the evidence from the larger study in Greece, which includes information only on mother's HBV status (Livadas et al 1979, reproduced here in Table 1). This study records a similar increase in sex ratio at birth associated with mother's HBV status as the two datasets Oster re-analyzes to conclude that elevated sex ratios at birth are related solely to father's HBV status. Unless there was a near-perfect correlation between mother's and father's 
HBV status, the data from Livadas et al's (1979) study would be inconsistent with Oster's reformulated hypothesis.

Her second approach uses population-level data from Taiwan (China). Using data on HBV prevalence by age from testing done in primary school, she constructs expected HBV prevalence by 5-year age cohort. She then examines the sex ratio of children born to parents who belong to different age cohorts, so their probability of infection differs. Once again, she finds that only the expected HBV of the father's cohort affects the sex ratio at birth. It is difficult to assess this information since she does not present basic information on the data, such as the number of agecohorts available for this analysis. ${ }^{9}$

Her third approach uses United States census data to look for patterns in the sex ratios of children born to Chinese immigrants, who are assumed to have levels of HBV prevalence similar to their place of origin. She finds that Chinese couples have an elevated sex ratio, as do Chinese men who marry non-Chinese. However, Chinese women who marry non-Chinese do not show an elevated sex ratio at birth. She interprets this as showing that only paternal HBV status drives the elevated sex ratio at birth. However, there could be a completely different explanation for this. The literature on son preference in China highlights the fact that people want sons in order to continue the husband's lineage - not that of the wife, since a woman cannot continue her own lineage. Even if married to an American-born woman, a Chinese-born man would still be subject to pressure to continue his lineage, but this would not apply to a Chinese-born woman married to an American-born man.

There are thus several questions that arise about Oster's evidence that it is the father's and not the mother's HBV status that causes the elevated sex ratios at birth. In any case, the demographic evidence below indicate that hepatitis B (whether of the father or the mother) cannot account, as Oster has argued, for the bulk of the female deficit in China.

\section{The Demographic Evidence}

\section{Whether a girl goes "missing" in China depends heavily on whether she has older sisters}

A very clear pattern emerges from the third of a million births in the one percent sample of the 1990 Chinese census. Note that this pertains to births during 1989-90, which is close in time to that for which Oster made her calculations on the proportion of the female deficit in China attributable to HBV (Oster 2005, Table 11). This enormous database of births shows that the only group of women with elevated probabilities of bearing a son is those who have already borne daughters (Figure 1). Those who have borne only son(s) show a mildly elevated probability of the next child being a girl — indicative of a mild preference for having a daughter if the sons are already safely in place.

A study of the sex ratio of aborted fetuses in China (Gu and Roy 1995, see Table 2) shows a pattern entirely consistent with that of the sex ratio of births - namely, that women who have only daughters account for the bulk of the excess of female fetuses among the total abortions. A similar pattern of son preference is found across Asia, showing that parental discrimination against girls is related to the sex composition of their children. Studies in India, Bangladesh, and South Korea, ${ }^{10}$ based on data from before the availability of sex-selection technology (when households resorted to infanticide or discrimination during early childhood), show that girls born 
to a family which already had a daughter suffered sharply elevated mortality compared to other children. After sex-selective technology became widely available, the South Asian and South Korean data indicate that the use of this technology is strongly correlated with the sex composition of existing children ${ }^{11}$ — just as in China.

It is striking that across East and South Asia all the indicators - sex ratios at birth, sex ratios of aborted fetuses, and sex ratios of child mortality - show the same pattern of manipulation of family composition by parents, consistent with strong son preference. Whether or not females "go missing" is determined by the existing sex composition of the family into which they are conceived. This suggests that cultural factors still provide the overwhelming explanation for the female deficit.

For Oster's hypotheses to be consistent with the demographic data, women (or their husbands) would have to be especially prone to contracting hepatitis B if they had borne a daughter. Or the disease would have to somehow lead to women first bearing daughters followed by an excess of sons. Either of these scenarios would require a much more complex set of biological factors to be at work than is indicated by Oster or by the micro-studies she cites.

Is it possible that somehow hepatitis B works in these very complex ways? Lin and Luoh's (2007) large medical dataset makes it possible to examine this issue. First, they show that the impact of maternal HBV status is fairly constant across birth orders (Figure 2). HBV+ and HBVwomen show a similar sharp rise in the sex ratio at birth by birth order. This is consistent with studies across Asia, which show that parents who have not yet borne a son have a higher probability of progressing to higher order births, and become increasingly desperate to assure that they have a son. ${ }^{12}$ The fact that the HBV impact is fairly constant across birth orders suggests that this impact is unaffected by the sex composition of previous births.

But Lin and Luoh (2007: Table 6) go further to test the possibility that some complex biological factor makes women who are HBV+ more prone to bearing a son if they had previously borne girls. Their findings do not support this hypothesis. For women who have a third birth, the sex ratios at birth of $\mathrm{HBV}+$ women remain marginally higher than that of HBV- women - but there is no significant additional impact of HBV status on the sex ratio at birth of the third child if the previous children were all female. Table 3 summarizes the sex ratios at birth by sex composition of previous births and mother's HBV status. It shows that women who have not yet borne a son have a much higher sex ratio of the third birth — but HBV status makes little difference to this.

\section{The population-level evidence from Africa}

Oster notes that Sub-Saharan Africa appears to offer evidence contrary to her hypothesis: "to the extent that it is possible to tell, it seems that Africa has relatively low sex ratios and relatively high HBV prevalence”. She notes that the absence of high-quality birth registration data from Africa make it difficult to use the data on sex ratios at birth. She therefore compiles data from the Demographic and Health Surveys (DHS) carried out in 18 Sub-Saharan African countries, cautioning that these survey data suffer from defects such as recall bias. She carries out some regressions on these data and concludes that "these results provide some comfort that Africa is not a particular challenge to the robustness of the HBV-sex ratio connection” (Oster 2005:1198).

But the limitations of African birth registration data apply also to many developing countries. This is why the DHS data are widely used to obtain estimates of the sex ratio at birth - including 
for India, a country which Oster analyzes extensively — and if anything the recall bias towards male births would be expected to be higher in India than in Sub-Saharan Africa given the stronger son preference in India. Also odd is the fact that she does not use Garenne's (2002) compilation and analysis of data on sex ratios at birth from 56 DHS surveys conducted in Sub-Saharan Africa. This covers 29 countries, since several countries had more than one survey spaced some years apart.

Neither Garenne's compilation of the DHS data nor the UN estimates show high sex ratios at birth in the African countries that Oster lists as having an especially high prevalence of HBV (Table 4). This is another piece of evidence that neither parent's HepB status makes a significant difference to the sex ratio at birth.

\section{Conclusions}

The Chinese data strongly support the cultural explanation for the female deficit — namely, that the high sex ratios at birth in China result largely from parental preference for sons. They show that whether or not females "go missing" depends heavily on the existing sex composition of the family into which they are conceived. Girls with no older sisters have similar chances of survival as boys. However, girls conceived in families which already have a daughter experience steeply higher probabilities of being aborted or of dying in early childhood.

The demographic data are very difficult to reconcile with Oster's hypothesis that most of the imbalance in the sex ratios at birth in China is attributable to the prevalence of hepatitis $\mathrm{B}$. Whether it is via the mother's infection status or the father's, the hepatitis B hypothesis is difficult to reconcile with the fact that the only group of women who have elevated probabilities of bearing a son are those who have already borne daughters.

Indeed, it is difficult to see how any biological hypothesis can explain a significant part of the imbalance in China's sex ratios at birth - given the strong relationship between the sex of children already born and the probability of the next child being a boy — unless it can be shown that the biological factor works in very complex ways such that it selectively affects those women (or men) who have borne girls, or causes them to first bear girls and then boys.

The medical data from Taiwan (China) are very interesting. Firstly, they show that hepatitis B infection raised women's probability of having a son by only 0.25 percent. Secondly, they show that the effect of HBV status is fairly constant across birth orders even though the sex ratio at birth rises sharply by birth order - suggests strongly that the impact of HBV status is unaffected by the sex composition of previous births. Thirdly, they show that HBV+ status does not selectively affect women who have borne girls — there is no significant additional impact of HBV status on the sex ratio at birth of the third child if the previous children were all female. This seems to rule out the possibility that biological factors can explain the complex patterns found in the demographic data.

Oster's hypothesis is interesting, but it cannot explain more than a very small part of the totality of the female deficit phenomenon in China. It appears that the governments of these countries have been correct to focus their policies on changing the cultural roots of son preference. 
Table 1. Offspring sex ratio by parental HBV infection: evidence from some micro-studies

\begin{tabular}{|c|c|c|c|c|}
\hline Location & HBV Status & Sons & Daughters & Sex Ratio \\
\hline \multirow[t]{2}{*}{ Greenland } & Positive & 64 & 60 & 1.07 \\
\hline & Negative & 174 & 194 & 0.90 \\
\hline \multirow{2}{*}{$\begin{array}{l}\text { Kar Kar } \\
\text { Island }\end{array}$} & Positive & 63 & 54 & 1.17 \\
\hline & Negative & 163 & 206 & 0.79 \\
\hline \multirow[t]{2}{*}{ Greece 1} & Positive & 90 & 51 & 1.77 \\
\hline & Negative & 287 & 255 & 1.13 \\
\hline \multirow[t]{2}{*}{ Philippines } & Positive & 66 & 41 & 1.61 \\
\hline & Negative & 304 & 301 & 1.01 \\
\hline \multirow[t]{2}{*}{ Greece 2} & Positive & 52 & 30 & 1.73 \\
\hline & Negative & 1006 & 955 & 1.05 \\
\hline \multirow[t]{2}{*}{ France } & Positive & 20 & 12 & 1.66 \\
\hline & Negative & 149 & 122 & 1.22 \\
\hline \multicolumn{5}{|c|}{$\begin{array}{l}\text { Notes: This table shows sex ratios among the children of carrier and non-carrier } \\
\text { parents in four regions. Data were collected by testing married women and, in } \\
\text { all cases except for Greenland, their husbands for HBV....The citations for each } \\
\text { study are as follows: Greenland - Drew, Blumberg and Robert-Lamblin (1986); } \\
\text { Kar Kar Island - Drew et al (1982); Greece } 1 \text { - Hesser, Economidou and } \\
\text { Blumberg (1975); Philippines - Chanazarian et al (1988); Greece } 2 \text { - Livadas et } \\
\text { al (1979); France - Cazal, Lemaire and Robinet-Levy (1976). }\end{array}$} \\
\hline
\end{tabular}

Source: Blumberg and Oster (2007: Table 1)

Note: The "Greece 2" study tested only women (not men) for HBV (Livadas et al 1979). The italicized sentence in the footnotes to the table above is incorrect. 
Table 2 Sex ratio of aborted fetuses by sex composition of existing children, southern Zhejiang Province, China, 1993. ( $N=10,782$ aborted fetuses)

\begin{tabular}{|c|c|c|}
\hline Existing children & \% of total abortions & Sex ratio of aborted fetuses \\
\hline None & & \\
\hline Sons only & 41.9 & 107.9 \\
\hline 1 & & 108.0 \\
\hline $2+$ & 23.7 & 97.6 \\
\hline Daughters only & 0.8 & 51.0 \\
\hline 1 & & 53.9 \\
\hline $2+$ & 29.0 & 106.5 \\
\hline Both sons \& daughters & 1.1 & \\
\hline & 3.5 & 86.7 \\
\hline All & & \\
\hline
\end{tabular}

Source: Das Gupta (2006), calculated from Gu and Roy (1995).

Note that the normal sex ratio of aborted fetuses is expected to be more masculine than the sex ratio at birth. This is because more males are conceived than females, and an excess of males among spontaneous abortions results in a more balanced sex ratio at birth. 
Table 3 Sex ratio at birth of the third child by sex composition of previous births, Taiwan (China), 1988-99

\begin{tabular}{|l|c|c|}
\hline Gender of previous two births & HBV+ mothers & HBV- mothers \\
\hline Both were girls & 122.4 & 121.4 \\
\hline At least one boy & 110.5 & 110.9 \\
\hline
\end{tabular}

Source: Lin and Luoh 2007: Table 6 and personal communication specifying the actual sex ratios underlying the regressions in Table 6 
Table 4. Sex ratios at birth, 1995-2000, for the Sub-Saharan African countries with high hepatitis B infection rates as listed in Oster (2005), Appendix B

\begin{tabular}{|l|c|c|}
\hline & DHS & UN \\
\hline Botswana & 0.98 & 1.03 \\
\hline Liberia & 1.05 & 1.03 \\
\hline Malawi & 1.01 & 1.03 \\
\hline Mali & 1.02 & 1.05 \\
\hline Togo & 1.02 & 1.02 \\
\hline Zimbabwe & 1.02 & 1.02 \\
\hline Sub-Saharan Africa & 1.04 \\
\hline $\begin{array}{l}\text { Sources: Col 1: Garenne (2002), calculated from the Demographic and Health } \\
\text { Surveys conducted on national samples of these countries. Where there was more than } \\
\text { one survey, that from the most recent year is shown. Col 2: Population Division of the } \\
\text { Department of Economic and Social Affairs of the United Nations Secretariat, World } \\
\text { Population Prospects: The 2004 Revision and World Urbanization Prospects: The } \\
\text { 2003 Revision, http://esa.un.org/unpp, 15 June 2005; 11:19:25 AM }\end{array}$ \\
\hline
\end{tabular}


Figure 1: Probability of bearing a son, by sex composition of woman's existing children, China 1990

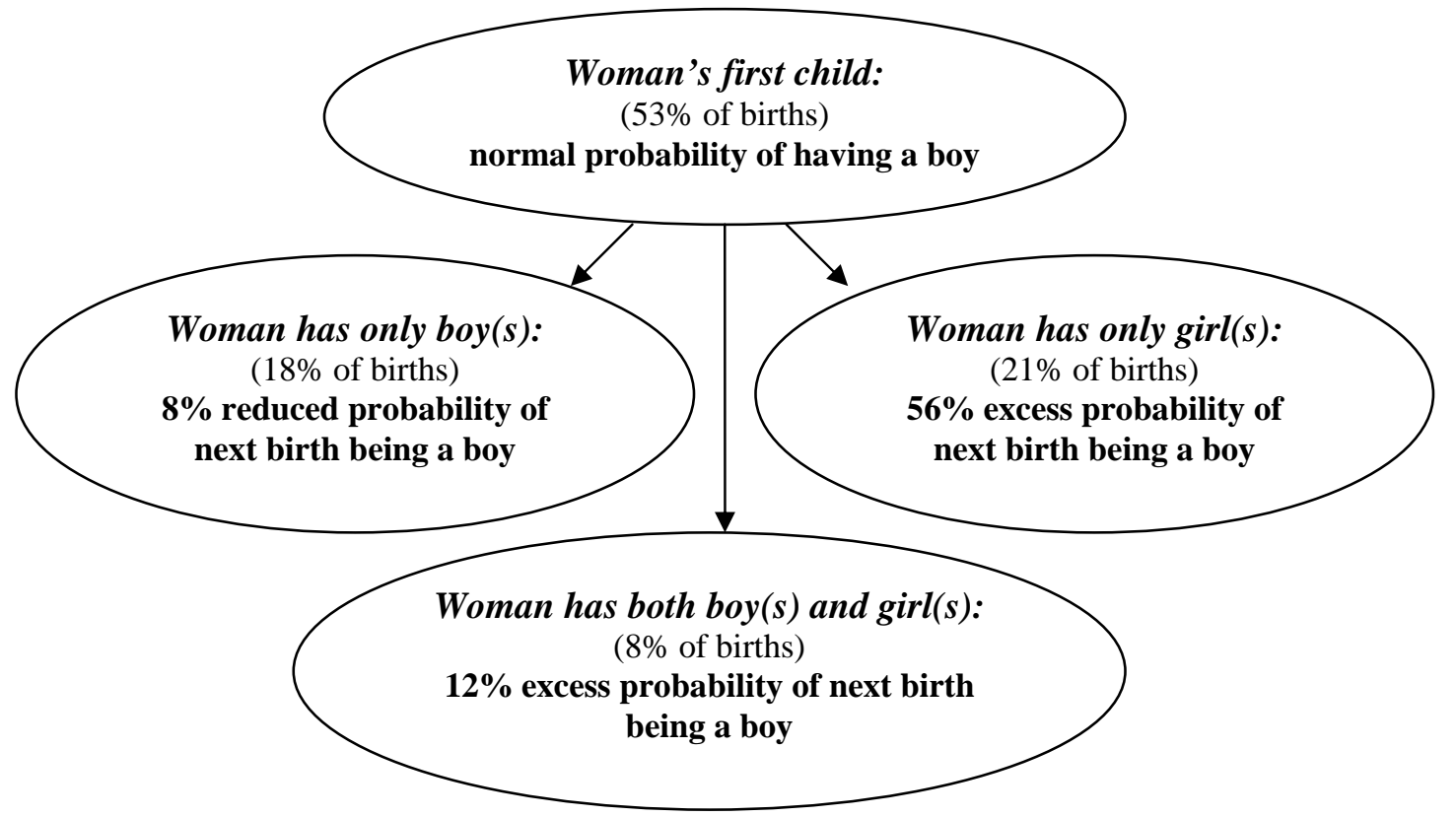

Source: Das Gupta (2006), calculated from Zeng et al (1993). 


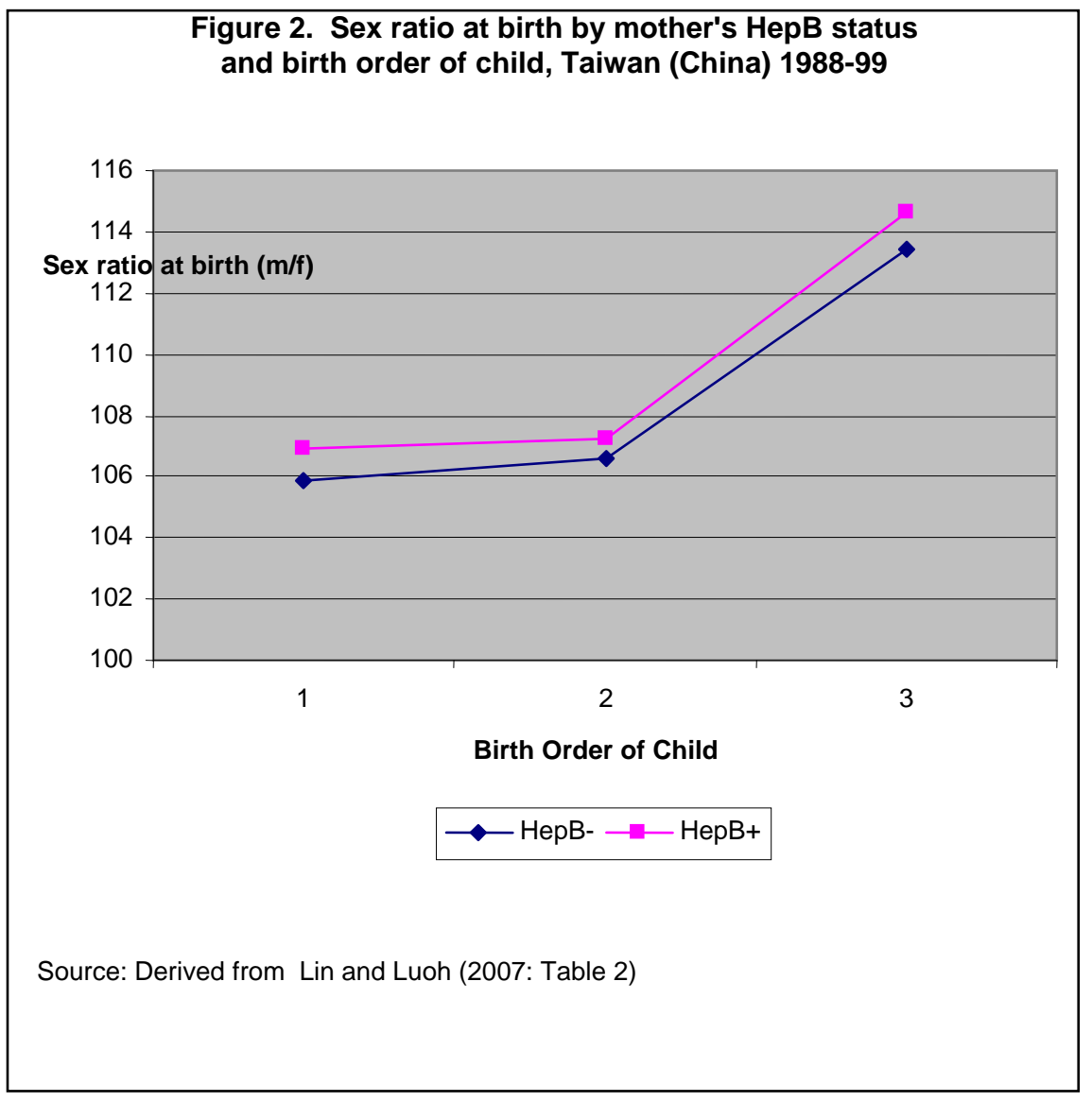




\section{References}

Arnold, Fred. Minja Kim Choe, and T.K. Roy. 1998. Son preference, the family-building process and child mortality in India, Population Studies 52(3):301-315

Arnold, Fred, Sunita Kishor, and T. K. Roy. 2002. "Sex-Selective Abortions in India." Population and Development Review 28(4):759-85.

Barro, Robert. 2005. “The Case of Asia's 'Missing Women’”, Business Week, February 28.

Blumberg, Baruch S. 2006a. The Curiosities of Hepatitis B virus: prevention, sex ratio, and demography, The Proceedings of the American Thoracic Society 3:14-20. http://pats.atsjournals.org/cgi/content/full/3/1/14\#TBL4\#TBL4

Blumberg, Baruch S. 1976. Australia Antigen and the Biology of Hepatitis B, Nobel Lecture Dec 13, 1976.

Blumberg, Baruch S., and Emily Oster. 2007. "Hepatitis B and Sex Ratios at Birth: Fathers or Mothers?” Processed. http://home.uchicago.edu/ eoster/HBVfathers.pdf

Cazal, P., J.M. Lemaire, and M. Robinet-Levy. 1976. "Hepatitis B et Rapport du Masculinite”, Revue Francaise de Transfusion et Immunomatologie, 19:577-581.

Chahnazarian, Anouch, Baruch S. Blumberg, and W.Thomas London. 1988. "Hepatitis B and the sex ratio at birth: a comparative analysis of four populations.” Journal of Biosocial Sciences 20(3):357-70.

Choe, Minja Kim. 1987. "Sex differentials in infant and child mortality in Korea.” Social Biology 34:12-25.

Choe, Minja Kim, G.Fei, W. Jiamming and Z. Ruyue.1992. "Progression to second and third births in China: patterns and covariates", International Family Planning Perspectives 18:130136.

Coale, Ansley J. 1991. "Excess Female Mortality and the Balance of the Sexes in the Population: An Estimate of the Number of "Missing Females" Population and Development Review 17(3):517-23.

Croll, Elisabeth, 2001. Endangered Daughters Discrimination and Development in Asia. Routledge.

Das Gupta, Monica. 1987. "Selective discrimination against female children in rural Punjab, India." Population and Development Review 13(1):77-100.

Das Gupta, Monica, Sunhwa Lee, Patricia Uberoi, Danning Wang, Lihong Wang, and Xiaodan Zhang. 2004. "State Policies and Women's Agency in China, the Republic of Korea and India 1950-2000: lessons from contrasting experiences”, in Vijayendra Rao and Michael Walton (eds.) Culture and Public Action: A Cross-Disciplinary Dialogue on Development Policy, Vijayendra Rao and Michael Walton (eds), Stanford-California: Stanford University Press.

Das Gupta, Monica. 2005. “.Explaining Asia’s ‘Missing Women’: A New Look at the Data.” Population and Development Review 31(3): 529-535.

Das Gupta, Monica. 2006. “Cultural versus Biological Factors in explaining Asia’s 'Missing Women': response to Oster”, Population and Development Review 32(2):328-332

Drew, Jean, W. Thomas London, Baruch S. Blumberg, and Susan Serjeanston. 1982. "Hepatitis B virus and sex ratio on Kar Kar Island”, Human Biology 54(1):123-135. 
Drew, J., B.S. Blumberg, and J. Robert-Lamblin. 1986. "Hepatitis B virus and sex ratio of offspring in East Greenland”, Human Biology, 58(1):115-120

Dubner, Stephen J., and Steven D. Levitt. 2005. "The Search for 100 Million Missing Women: An economics detective story.” Slate, May 24.

Garenne, Michel. 2002. "Sex ratios at birth in African populations: A review of survey data," Human Biology 74: 889-900

Gu, Baochang, and Krishna Roy. 1995. Sex Ratio at Birth in China, with Reference to Other Areas in East Asia: What We Know, Asia-Pacific Population Journal 10(3):17-42

Hansen, Dorthe, Henrik Moller, and Jorn Olsen. 1999. "Severe periconceptional life events and the sex ratio in offspring: follow up study based on five national registers.” British Medical Journal 319: 548-9.

Hesser, Jana, Ionna Economidou, and Baruch S. Blumberg. 1975. Hepatitis B surface antigen (Australia antigen) in parents and sex ratio of offspring in a Greek population, Human Biology 47: 415-425.

Hsu, Francis. 1948. Under the Ancestors' Shadow. New York: Columbia University Press.

Johansson, Sten, and Ola Nygren. 1991. "The Missing Girls of China: A New Demographic Account.” Population and Development Review 17(1):35-51.

Klasen, Stephan. 2002. "A Turning Point in Gender Bias in Mortality? An Update on the Number of Missing Women”. Population and Development Review 28: 285-312 (2002).

Klasen, Stephan. 2005. "Comments on Paper by Emily Oster: Hepatitis B and the Case of the Missing Women" (http://www.iai.wiwi.uni-goettingen.de/klasen/CommentsOster.pdf).

Larsen, Ulla, Woojin Chung, and Monca Das Gupta. 1998. "Fertility and Son Preference in Korea”, Population Studies 52(3):317-325

Lin, Ming-Jen and Ming-Ching Luoh. 2007. "Can Hepatitis B Mothers Account for the Number of Missing Women? Evidence from Three Million Newborns in Taiwan.” National Taiwan University, Department of Economics, processed.

Livadas, D., J. Economidou, J.E. Hesser, D.A. Koutras, and S. Hadziyannis. 1979. "Fertility and sex ratio of offspring of female HBsAg carriers", Journal of the Royal Society of Medicine 72:509-512

Muhuri, Pradip K., and Samuel H. Preston. 1991. "Effects of Family Composition on Mortality Differentials by Sex Among Children in Matlab, Bangladesh.” Population and Development Review 17(3):415-34.

Oster, Emily. 2005. "Hepatitis B and the case of the missing women.” Journal of Political Economy 113(6):1163-1216

Oster, Emily. 2006. “On Explaining Asia’s ‘Missing Women’: Comment on Das Gupta.” Population and Development Review 32(2): 323-327.

Park, Chai-Bin and Nam-Hoon Cho. 1995. "Consequences of son preferences in a low-fertility society: imbalance of the sex ratio at birth in Korea.” Population and Development Review 21(1):59-84.

Sen, Amartya. 1990. "More than 100 million women are missing." New York Review of Books, 20 Dec 61-66. 
Vlassoff, C. and Bonilla, E. 1994. "Gender related differences in the impact of tropical diseases on women: what do we know?” Journal of Biosocial Science 26: 37-53.

Waldron, Ingrid. 1983. "The role of genetic and biological factors in sex differences in mortality.” In Alan Lopez and Lado Ruzicka (eds.) Sex Differentials in Mortality. Canberra: Australian National University Press.

Xinhua 2006. "China promotes girls to avoid glut of bachelors”, China Daily 8 August 2006 http://www.chinadaily.com.cn/china/2006-08/08/content_660041.htm

Zeng Yi, Tu Ping, Gu Baochang, Xu Yi, Li Bohua, and Li Yongping. 1993. "Causes and implications of the recent increase in the reported sex ratio at birth in China." Population and Development Review 19(2):283-302. 


\section{Endnotes}

${ }^{1}$ See Sen (1990), Coale (1991) and Klasen (2002) for estimates of the numbers of "missing women” around the world. China and India make up the vast majority of these "missing women".

${ }^{2}$ See Croll (2000) and Das Gupta et al (2004).

${ }^{3}$ See, for example, Waldron (1983), Vlassoff and Bonilla (1994), and Hansen et al (1999).

${ }^{4}$ Johansson and Nygren (1991).

${ }^{5}$ See Klasen (2005) for a fuller critique of her data and methods.

${ }^{6}$ The figures are from the Taiwan Demographic Fact Book, various issues. I am grateful to Ming-Jen Lin for these figures.

${ }^{7}$ See for example Barro (2005), and Dubner and Levitt (2005).

${ }^{8}$ The paper is co-authored with the medical scientist Baruch Blumberg, but the analytical methods used are those of the social and not the biological sciences, so it appears to be primarily Oster's work.

${ }^{9}$ She mentions that she uses data collected from school testing done in the early 1990s (Blumberg and Oster 2007: Table 4), and that the data on births are until 2002. Also, the parents must belong to different age cohorts, and both parents' age-cohorts must have been in school in the early 1990s when the testing was done. Women are typically younger than their husbands, so the number of children born to the wives of men who were still in school in the early 1990s may not be large.

${ }^{10}$ See for example, Das Gupta (1987) on India, Muhuri and Preston (1991) on Bangladesh, and Choe (1987) on South Korea.

${ }^{11}$ Arnold et al. 2002), Park and Cho (1995).

${ }^{12}$ See for example Choe et al (1992) on China, Arnold et al (1998) on India, and Larsen et al (1998) on South Korea. 